\title{
P wie Personalkosten
}

Wer seine Finanzbuchhaltung selbst erstellt, muss monatlich auch die anfallenden Personalkosten verbuchen. Hierfür stehen zwei Methoden zur Verfügung. Welche der Zahnarzt anwendet, hängt von verschiedenen Vorgaben ab.

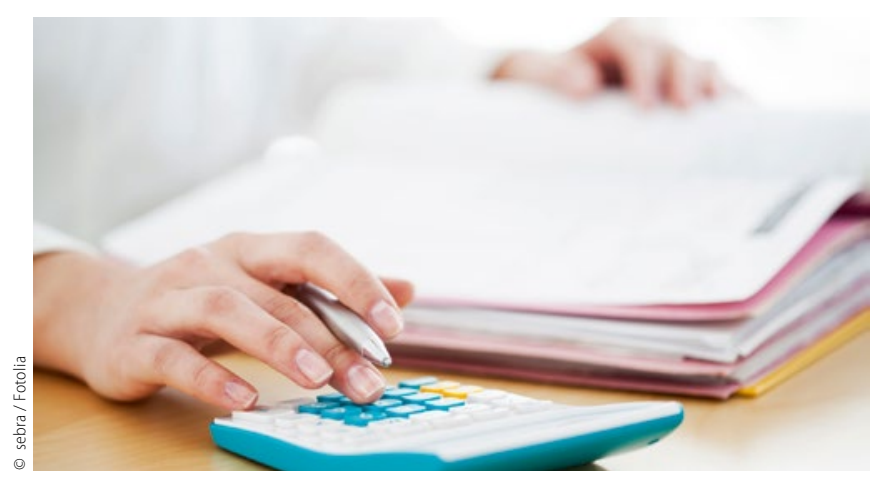

Beim Blick auf die Liste der bebuchten Konten beziehungsweise den Kontenplan entdeckt man häufig, dass Personalkonten nicht nur wie zu erwarten im Kostenbereich (SKR03: Kontenklasse 4) zu finden sind, sondern auch als Verbindlichkeitskonten, im SKR 03 in der Kontenklasse 1 (zum Beispiel 1740, Verbindlichkeiten aus Lohn und Gehalt).

Diese zusätzlichen Konten werden bei der sogenannten „Bruttomethode" verwendet, bei der mit der Erstellung der Gehaltsabrechnung aus der Abrechnungssoftware heraus bereits $\mathrm{Bu}$ chungssätze für die Finanzbuchhaltung erstellt werden. Dabei werden die Personalkosten inklusive Arbeitgeberanteilen auf den Aufwandskonten erfasst, die Gegenbuchung erfolgt auf Verbindlichkeitskonten (zum Beispiel: 4100 Gehälter an 1740 Verbindlichkeiten Lohn/Gehalt). Diese Buchungssätze können in die Finanzbuchhaltung übernommen werden. Es werden also zum Zeitpunkt der Abrechnung bereits Kosten verbucht, denen jedoch Verbindlichkeiten in gleicher Höhe gegenüber stehen.

Bei der später erfolgenden Zahlung der Gehälter, Steuern und Abgaben wird als Gegenkonto das jeweilige Verbindlichkeitskonto angesprochen (zum Beispiel 1740 Verbindlichkeiten Lohn/Gehalt an 1200 Bank). Danach ist das Verbindlichkeitskonto ausgeglichen.

Dem gegenüber erfolgt bei der Anwendung der „Nettomethode" die Verbuchung der Lohn-, Steuer- und Abgabenzahlungen zum Zeitpunkt der Zahlung aus dem Bankkonto heraus direkt gegen die Aufwandskonten (4100 Gehälter an 1200 Bank).

\section{Nettomethode für Überschussrechner}

Warum gibt es aber diese beiden unterschiedlichen Methoden? Da es bei der Berechnung, Belastung und Erstattung von Abgaben im Personalbereich ständig zu Abweichungen oder rückwirkenden Änderungen kommt, ist eine Prüfung der ordnungsgemäßen Abführung der berechneten Abgaben oft umständlich. Mit der Bruttomethode ist ein Abgleichen der entsprechenden Konten meist einfacher. Bei Unternehmen, die bilanzpflichtig sind, erscheint diese Erfassung der Kosten zum Zeitpunkt der Entstehung auch steuerlich richtig zu sein. Anders sieht dies jedoch bei der Gewinnermittlung im Rahmen der EinnahmenÜberschuss-Rechnung aus, da hierbei Kosten und Erlöse im Grundsatz nach dem Zeitpunkt des Zahlungsflusses und nicht nach dem Zeitpunkt der Entstehung gebucht werden.

Die Anwendung der Nettomethode ist zulässig und für sogenannte Überschussrechner völlig korrekt, auch wenn die meisten Steuerberater die Bruttomethode bevorzugen. Bei überschaubarem Personalbestand ist ein Abgleichen der Konten auch bei der Nettomethode unproblematisch. Im Zweifelsfall ist eine Rücksprache mit dem Steuerberater sinnvoll, welche Methode zu wählen ist. Keinesfalls sollte aber im laufenden Jahr nahtlos von einer zur anderen Methode gewechselt werden (also: zunächst Erfassung gegen die Aufwandskonten, später über Verbindlichkeiten). Unterjährig muss die angewandte Methode konstant durchgebucht werden.

In jedem Fall ist die ordnungsgemäße Verbuchung der Personalkosten eine klärende Absprache mit dem Steuerbüro wert.

Mehr Infos unter www.fibu-doc.de

Das in den Artikeln dargestellte Buchhaltungskonzept basiert auf der zahnarztspezifischen Buchhaltungssoftware fibu-doc und wird vom FVDZ unterstützt.

\section{Seminare \\ Der Blick in die Praxiszahlen \\ 26.10.2016, Düsseldorf \\ Personalmanagement \\ 11.11.2016, Berlin \\ Der Blick in die Praxiszahlen \\ 30.11.2016, Leipzig}

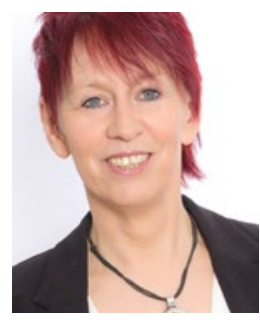

Barbara Mertens

www.fibu-doc.de 